\title{
Management of children's acute diarrhea by community pharmacies in five towns of Ethiopia: simulated client case study
}

This article was published in the following Dove Press journal:

Therapeutics and Clinical Risk Management

5 April 2016

Number of times this article has been viewed

\section{Tadesse Melaku Abegaz' \\ Sewunet Admasu Belachew' \\ Tamrat Befekadu Abebe' \\ Begashaw Melaku \\ Gebresilassie \\ Fitsum Sebsibe Teni ${ }^{2}$ \\ Habtamu Gebremeskel Woldie ${ }^{3}$ \\ 'Department of Clinical Pharmacy, School of Pharmacy, Gondar University, Gondar, ${ }^{2}$ Department of Pharmaceutics and Social Pharmacy, School of Pharmacy, College of Health Sciences, Addis Ababa University, Addis Ababa, ${ }^{3}$ Department of Hospital Pharmacy, Debremarkos Teaching and Referral Hospital, Debremarkos, Ethiopia}

\section{Video abstract}

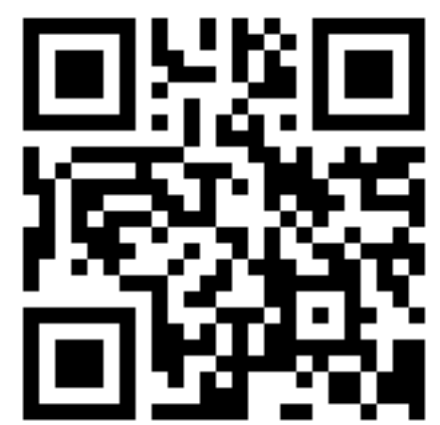

Point your SmartPhone at the code above. If you have a $Q R$ code reader the video abstract will appear. Or use: http://youtu.be/Sx3ECGLybXE

Correspondence: Tadesse Melaku Abegaz Department of Clinical Pharmacy, School of Pharmacy, Gondar University, 15 Bekafa street, PO Box 196, Gondar, Ethiopia

Tel +25I 9857975

Email melakutadesse98@gmail.com
Background: Acute diarrhea is the major cause of child morbidity and mortality in low-income nations. It is the second most common cause of death among children $<5$ years of age globally. The indispensable role of community pharmacists is clearly observed in the prevention and treatment of diarrhea. However, there is a paucity of data on how community pharmacies manage acute childhood diarrhea cases in Ethiopia. This study aimed to evaluate the experience of community pharmacies in the management of acute diarrhea in northern Ethiopia.

Methods: A simulated case-based cross-sectional study was conducted in community pharmacies from five towns of northern Ethiopia between April 2015 and September 2015. Convenience sampling technique was used to select sample towns. A structured questionnaire was organized to collect the information. Descriptive statistics, chi-squared test, one-way analysis of variance, and binary logistic regression were performed to describe, infer, and test for association between the variables. SPSS for Windows Version 21 was used to enter and analyze the data. A 95\% confidence interval and $P$-value of 0.05 were set to test the level of significance.

Results: Approximately 113 community pharmacies were visited to collect the required data from five towns. Majority $(78,69 \%)$ of them were located away from hospitals and health care areas. Nine components of history taking were presented for dispensers. Regarding the patient history, "age" was frequently taken, $(90.3 \%)$, whereas "chief complaint" was the least to be taken (23\%), for patients presenting with diarrhea. Approximately $96(85.0 \%)$ cases were provided with one or more medications. The remaining 17 (15\%) cases did not receive any medication. A total of six pharmacologic groups of medications were given to alleviate acute diarrheal symptoms. Majority $(66,29.6 \%)$ of the medications were oral rehydration salts with zinc. The mean number of medications was 1.99 per visit. Components of advice, such as dose, frequency, duration, drug action, and adverse drug reactions, were found to vary among the five towns at a statistically significant level.

Conclusion: Community pharmacies provided inadequate treatment for acute childhood diarrhea. Inappropriate history taking and incorrect drug and food instructions have been frequently encountered during acute diarrhea management. Practitioners working in northern Ethiopia should receive proper training on the management of acute childhood diarrhea.

Keywords: acute diarrhea, children, community pharmacies, simulated case, northern Ethiopia

\section{Introduction}

Discharge of loose stools more than three times per day for not $>3$ weeks is considered to be acute diarrhea. ${ }^{1}$ It is the second most common cause of death among children $<5$ years of age globally. Southeast Asia and Africa harbored $80 \%$ of diarrhea cases. $^{2}$ According to the World Health Organization (WHO) report, Africa accounted for $98.2 \%$ of the total global acute watery diarrhea (AWD). Acute diarrhea is emerging 
as a major public health issue and development challenge in poor countries. ${ }^{3}$ Low-income countries such as Ethiopia are suffering from diarrhea epidemic due to poor prevention through personal hygiene, lack of skilled man power to treat the epidemic, and lack of medications.

Approximately one of every five deaths every year in Ethiopia has been due to diarrheal disease in the past 10 years. Its occurrence is highest particularly in children $<2$ years of age. ${ }^{4}$ This is due in part to declining level of maternal acquired antibodies after holding breastfeeding. ${ }^{4}$ Active immunity in the child is still not matured to defend pathogenic antigens. Children of this age group are exposed to contamination with feces when they start to crawl. ${ }^{5}$ Death from acute diarrhea arises from complications such as dehydration and acidosis. However, it can be ultimately prevented by supplementing oral and parenteral rehydration, depending on the extent of fluid and electrolyte losses. The WHO recommends increased fluids and supplemental zinc for 10-14 days to prevent dehydration. ${ }^{6}$ Antibiotic therapy directed at the specific pathogen is also recommended. Rehydration and antibiotic therapy are frequently initiated by community pharmacists who do have the mandate to exercise these activities in a certain community.

Community pharmacies are frequently visited by the public to answer health-related queries as they are easily reachable and dispense drugs legally and ethically. ${ }^{1}$ They have been considered the preferred source of health information, advice, and services for common health problems in local communities. ${ }^{7}$ Community pharmacists solve common ailments of the public because they encounter the same and repeated cases of a certain community. ${ }^{8}$

Indispensable role of community pharmacists is clearly observed in the prevention and treatment of diarrhea and the associated problem of dehydration in children. ${ }^{9}$ They play a pivotal role in the management of acute diarrhea and referral of complicated and advanced cases to higher health facilities for laboratory investigation and intravenous resuscitation. However, the treatment protocol of acute diarrhea is ever changing. New guidelines are published every day in the world. Community pharmacists are not able to access those guidelines due to remote geographical locations of pharmacies. Procedures to update pharmacists' knowledge are also not well established. Hence, pharmacists are forced to manage diarrheal disease using old trends. Research from developing countries showed that dispensers working in community pharmacies rarely possess the adequate knowledge and skills for effective disease management. ${ }^{10}$ Poor history taking, inadequate information provision, poor consultations, and poor case management of childhood diarrhea were found to be the common shortcomings of pharmacists and pharmacy staff in both developed and developing countries. ${ }^{7}$ To date, emphasis is not given for the role of community pharmacists in the management of common health problems, including diarrhea cases. Capacity building including the supply of guidelines and trainings to fill the knowledge gap of pharmacist was undermined. Strengthening the power of these pharmacies requires a great area of concern. Training of community pharmacists on the management of common disease states was occasionally carried out. Moreover, these interventions were not comprehensive enough to include acute diarrhea, which is the most prevalent common public health problem. These short-term trainings were also not inclusive of all community pharmacists. The Federal Ministry of Health, Ethiopia, has set out National Acute Water Diarrhea Prevention and Control Strategy to free Ethiopia from AWD by the end of 2015 . However, the strategy was not fully implemented, and the majority of the activities were limited to the central part of the country. ${ }^{3}$ There is a paucity of data on how community pharmacies manage acute childhood diarrhea case in Ethiopia. This study aimed to evaluate the experience of community pharmacies of history taking, medication recommendation, and drug information provision for hypothetical acute childhood diarrhea in northern Ethiopia.

\section{Methods}

\section{Study population and study area}

This study was conducted in northern Ethiopia. Ethiopia is a low-income country located in the Horn of Africa. Community pharmacists and druggists who were working in selected community pharmacies were included in the study. The study populations were all community pharmacy outlets in selected towns. The study sites were selected based on the number of patients encountered by community pharmacies and the geographical locations of pharmacies in the northern part of the country. Accordingly, the data were collected from five towns of Amhara and Tigray regions. Two cities in Tigray regional state, namely, Mekele and Shrie, were studied. The two towns were found to host many cases of diarrhea from Affar and Humora, respectively. In Amhara region, three towns, including Bahir Dar, Gondar, and Dessie were taken. The last three towns were having a large population. These three towns have large population sizes and have hospitals serving as referral institutions for patients from neighboring towns (Figure 1). 


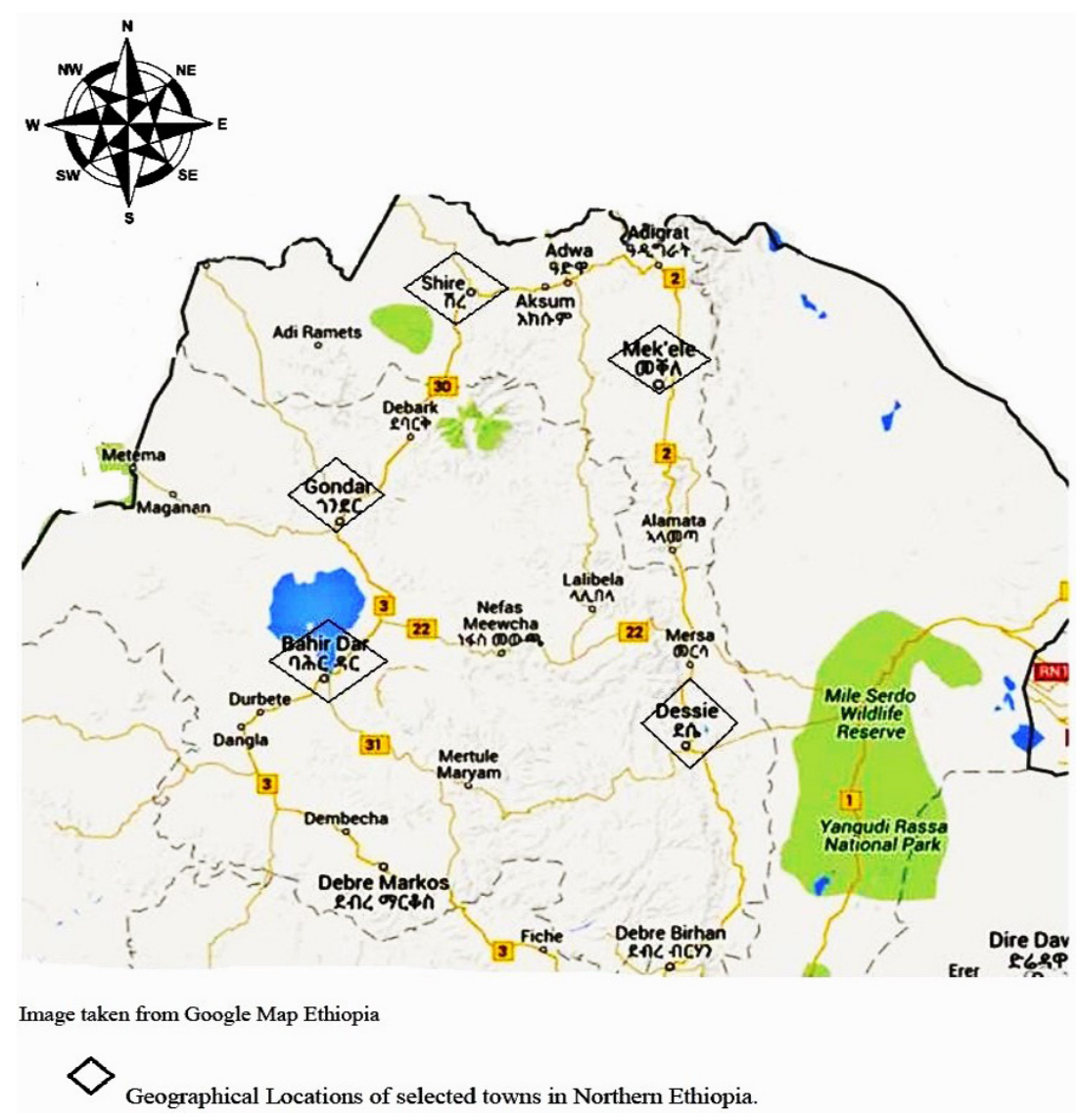

Figure I Geographical locations of study sites.

\section{Study design and study period}

A simulated case-based cross-sectional study was conducted in community pharmacies from five towns of northern Ethiopia between April 2015 and September 2015.

\section{Variables}

Location of pharmacies in a town, types of dispensers, and the study towns were regarded as independent variables, whereas medication recommendation and information provided to customers, instructions on food and fluid intake, history taking, and outcome from visit were the dependent variables.

\section{Sampling technique and sample size determination}

Considering the higher proportions of patient load and based on the geographical location of the community pharmacies over the regions, five sample towns were selected from two regional states of Ethiopia. Convenience sampling technique was used to select the sample towns. All pharmacies in the study towns were included to collect the required data.

\section{Data collection procedure}

Data were collected by all the investigators who were working as instructors at University of Gondar. Ethical clearance was obtained from the Ethical Review Committee of School of Pharmacy, College of Medicine and Health Sciences, University of Gondar. A structured questionnaire was prepared to collect information on the knowledge and practice of community pharmacists in the management of AWD in children $<5$ years old. The protocol for assessing the practice of pharmacists regarding evaluation of patients, treatment, and instruction on food and fluid intake was taken from WHO guideline information for pharmacists. ${ }^{2}$ Data collectors were trained on simulated patient case by the principal investigator as if they were close relatives of under-five children. They went to community pharmacies with dispensers on duty and asked for medication for their child. They were also informed on how to interact with the pharmacists and what answers to give for anticipated evaluation questions on the history of present illness.

\section{Data entry, analysis, and interpretation}

The data were checked for consistency and completeness every day on the sites by the investigators. Data entry and 
analysis were done using SPSS Version 21 for Windows. Descriptive statistics, such as frequency and percentage, were performed to determine the number of pharmacies in each city, group of drugs recommended, and other findings. Mean and standard deviations were computed to describe the difference in drug information provision, group of drugs dispensed, and history taking between towns. Likelihood ratios were applied to interpret the results of $\chi^{2}$ test. $P$-value was set at 0.05 with $95 \%$ confidence intervals (CIs) to test statistically significant difference and association between variables. Mean square values, $F$-test, and $P$-values were used to report the inference. Logistic regression was found as an appropriate statistical method done to test whether dispenser qualification, location of pharmacies, and town in any place affect the extent of community pharmacies giving drug for each case visit.

\section{Ethics}

The study was approved by the ethical review committee of the School of Pharmacy, College of Medicine and Health Sciences, University of Gondar.

\section{Operational definitions}

Away from hospital: it is the location of pharmacies where the pharmacist is not able to refer the patient in case it is necessary.

Outcome from visit: the type of interventions provided by community pharmacies.

Dispenser: anyone including pharmacist, druggist, pharmacy technician, or salesperson who was working at community pharmacies.

Community pharmacy: an establishment retailing medicines which is managed by a pharmacist registered with a relevant body and licensed to dispense medicines for humans and compound prescribed preparations.

\section{Results \\ Geographic locations of community pharmacies and study towns}

Approximately 113 community pharmacies were visited to collect the required data from five towns. The simulated visits to all the pharmacies were included in the final analysis. Twentytwo pharmacies were taken from Mekele, which is located in Tigray regional state. In the same regional state, 20 pharmacies were visited from Shire. In Amhara regional state, a total of 71 pharmacies were included from three towns, namely, Bahir Dar (28), Dessie (22), and Gondar (21). Community pharmacies were classified into two groups based on their proximity to health facilities. Majority $(78,69 \%)$ of them were located away from hospitals and other health institutions. Statistical difference was observed between the towns in the number of pharmacies located away from or near to hospitals $\left(\chi^{2}=30.9\right.$, $P=0.00)$. Twenty pharmacies out of 22 were located away from hospitals at Mekele. In contrast to this, a large number of community pharmacies were found close to hospitals at Shire.

\section{Qualifications of dispensers working at community pharmacies}

The number of pharmacists $(45,39.8 \%)$ was less than that of druggists $(68,60.2 \%$; Table 1$)$. The ratio of druggists and pharmacists was significant between the five cities $\left(\chi^{2}=9.8\right.$, $P=0.04)$. The ratio was highest in Bahir Dar (2.5) as compared to other cities. The least druggist-to-pharmacist ratio was observed at Mekele (0.7) (Table 1).

\section{Experience of community pharmacies of history taking about acute diarrhea}

Nine components of history taking were presented for dispensers. Individual history taking components that included chief complaint, weight, medication history, past medical history, age, onset and duration of diarrhea, frequency of

Table I Statistical test $\left(\chi^{2}\right.$ test) of the location of community pharmacies and qualification of dispensers in five towns of northern Ethiopia in $2015(\mathrm{n}=113)$

\begin{tabular}{|c|c|c|c|c|c|c|c|c|c|c|}
\hline \multirow[t]{2}{*}{ Towns } & \multicolumn{2}{|c|}{ Location of pharmacies } & \multirow[t]{2}{*}{ Total } & \multirow[t]{2}{*}{$\chi^{2}$} & \multirow[t]{2}{*}{$P$-value } & \multicolumn{2}{|c|}{ Qualification of dispensers } & \multirow[t]{2}{*}{ Total } & \multirow[t]{2}{*}{$\chi^{2}$} & \multirow[t]{2}{*}{$P$-value } \\
\hline & $\begin{array}{l}\text { Away from } \\
\text { hospital (\%) }\end{array}$ & $\begin{array}{l}\text { Near to } \\
\text { hospital (\%) }\end{array}$ & & & & Pharmacist & Druggist & & & \\
\hline Gondar & I7 (80.9) & $4(19.1)$ & 21 & 30.9 & $0.00 * *$ & II (52.4) & $10(47.6)$ & 21 & 9.8 & $0.04 *$ \\
\hline Mekele & $20(90.9)$ & $2(9.1)$ & 22 & - & - & $13(59.1)$ & $9(40.9)$ & 22 & - & - \\
\hline Bahir Dar & $23(82.1)$ & $5(17.9)$ & 28 & - & - & $8(28.6)$ & $20(71.4)$ & 28 & - & - \\
\hline Shire & $4(20)$ & $16(80)$ & 20 & - & - & $4(20.0)$ & $16(80.0)$ & 20 & - & - \\
\hline Dessie & $14(63.6)$ & $8(36.4)$ & 22 & - & - & $9(40.9)$ & $13(59.1)$ & 22 & - & - \\
\hline Total & 78 (69) & $35(3 I)$ & 113 & - & - & 45 (39.8) & $68(60.2)$ & 113 & - & - \\
\hline
\end{tabular}

Notes: *Significant at 0.05 . ** Significant at 0.01 . 
Table 2 The components of history taking done by community pharmacies for simulated acute diarrhea cases before providing therapy at five towns of northern Ethiopia in $2015(\mathrm{n}=\mathrm{I} 13)$

\begin{tabular}{|c|c|c|c|c|c|c|c|c|}
\hline \multirow[t]{2}{*}{ History taking } & \multicolumn{5}{|l|}{ Towns } & \multirow[t]{2}{*}{ Total } & \multirow[t]{2}{*}{$\chi^{2}$} & \multirow[t]{2}{*}{$P$-value } \\
\hline & Gondar & Mekele & Bahir Dar & Shire & Dessie & & & \\
\hline \multicolumn{9}{|l|}{ Chief complaint } \\
\hline Yes (\%) & $5(23.8)$ & $0(0)$ & 5 (17.9) & $0(0)$ & $16(27.3)$ & $26(23)$ & 17.1 & $0.02 *$ \\
\hline No (\%) & $16(76.2)$ & $22(100)$ & $23(82.1)$ & $20(100)$ & $6(72.7)$ & $87(77)$ & & \\
\hline \multicolumn{9}{|l|}{ Weight } \\
\hline Yes (\%) & $2(9.5)$ & $6(27.3)$ & $6(21.4)$ & $0(0)$ & $12(54.5)$ & $26(23)$ & 23.5 & $0.00 * *$ \\
\hline No (\%) & $19(90.5)$ & $16(72.4)$ & $22(78.6)$ & $20(100)$ & $10(45.5)$ & 87 (77) & & \\
\hline \multicolumn{9}{|l|}{ Medication history } \\
\hline Yes (\%) & $5(23.8)$ & $6(27.3)$ & $5(17.9)$ & $0(0)$ & II (50) & 27 (23.9) & 18.7 & $0.01 * *$ \\
\hline No (\%) & $16(76.2)$ & $16(72.4)$ & $23(82.1)$ & $20(100)$ & II (50) & $86(76.1)$ & & \\
\hline \multicolumn{9}{|c|}{ Past medical history } \\
\hline Yes (\%) & $2(9.5)$ & $10(45.5)$ & $4(13.3)$ & $7(35)$ & I8 (8I.8) & $4 I(36.3)$ & 34.8 & $0.00 * *$ \\
\hline No (\%) & $19(90.5)$ & $12(54.5)$ & $24(85.7)$ & $13(65)$ & $4(18.2)$ & $72(63.7)$ & & \\
\hline \multicolumn{9}{|l|}{ Age } \\
\hline Yes (\%) & $19(90.5)$ & $22(100)$ & $26(92.9)$ & $20(100)$ & $15(68.2)$ & $102(90.3)$ & 17.0 & $0.002^{* *}$ \\
\hline No (\%) & $2(9.5)$ & $0(0)$ & $2(7.1)$ & $0(0)$ & 7 (3I.8) & II (9.7) & & \\
\hline \multicolumn{9}{|c|}{ Onset and duration of diarrhea } \\
\hline Yes (\%) & I5 (7I.4) & 17 (77.3) & I8 (64.3) & $18(90)$ & $8(36.4)$ & $76(67.3)$ & 15.9 & $0.003^{* *}$ \\
\hline No (\%) & $6(23.6)$ & $5(22.7)$ & $10(35.7)$ & $2(10)$ & $14(63.6)$ & 37 (32.7) & & \\
\hline \multicolumn{9}{|c|}{ Frequency of diarrhea } \\
\hline Yes (\%) & $6(28.6)$ & $8(36.4)$ & $5(17.9)$ & $15(75)$ & 16 (72.7) & $50(44.2)$ & 26.6 & $0.00 * *$ \\
\hline No (\%) & I5 (7I.4) & $14(63.6)$ & $23(82.1)$ & $5(25)$ & $6(27.3)$ & $63(55.8)$ & & \\
\hline \multicolumn{9}{|c|}{ Presence of blood in stool } \\
\hline Yes (\%) & $16(76.2)$ & $4(18.2)$ & $13(46.4)$ & II (55) & $12(54.5)$ & $56(49.6)$ & 16.2 & $0.003^{* *}$ \\
\hline No (\%) & $5(23.8)$ & I8 (8I.8) & $15(53.6)$ & $9(45)$ & $10(45.5)$ & $57(50.4)$ & & \\
\hline \multicolumn{9}{|l|}{ Fever } \\
\hline Yes (\%) & II (52.4) & $10(45.5)$ & $4(14.3)$ & $8(40)$ & $14(63.6)$ & 47 (4I.6) & 15.3 & $0.004 * *$ \\
\hline No (\%) & $10(47.6)$ & $12(5 \mid .5)$ & $24(85.7)$ & $12(60)$ & $8(36.4)$ & $66(58.4)$ & & \\
\hline
\end{tabular}

Notes: *Significant at 0.05 . * Significant at 0.01 .

diarrhea, presence of blood in stool, and fever have shown a significant variation in each town. Age was a frequently taken history for patients with diarrhea $(90.3 \%)$, whereas chief complaint was the least to be taken (16.5\%). The mean (m) number of history taking was $4.7 \pm 1.67$ histories per encounter (Table 2). There was a statistically significant difference in the mean number of histories taken by community pharmacies between the towns $(F=3.79, P=0.006)$. Post hoc analysis revealed that community pharmacies at Dessie $(\mathrm{m}=5.5 \pm 1.9)$ took more history than those at Bahir Dar $(\mathrm{m}=3.9 \pm 1.3, P=0.004)$ (Table 3).

\section{Medication recommendations of community pharmacies to clients}

A total of six pharmacologic groups of medications were given to alleviate acute diarrheal symptoms. These drugs include antiamoebic, antibacterial, antidiarrheal, anthelmintic, antispasmodic, oral rehydration salts (ORS), and zinc. Specific drugs such as cotrimoxazole, metrinidazole, loperamide, albendazole, mebendazole, and hyocine were dispensed. Approximately 223 drugs were dispensed to all encountered simulated cases (Figure 2). Majority $(66,29.6 \%)$ of the medications were ORS with zinc. Nearly $90.9 \%$ of cases were managed by ORS with zinc at Mekele, which was the highest among the cities. The rate of ORS plus zinc use was only $57.1 \%$ in the case of Dessie (Table 4). Antibacterials were the second most prescribed drugs. Antibacterial prescription pattern was significantly different between the towns $\left(\chi^{2}=40.4, P=0.00\right)$. Approximately $75 \%$ of cases were given antibacterial drugs at Bahir Dar, whereas only $18 \%$ of cases were treated with

Table 3 The mean number of histories taken by community pharmacies at each diarrheal visit in five towns of northern Ethiopia in $2015(n=113)$

\begin{tabular}{llll}
\hline Towns & \multicolumn{1}{l}{ History taking } & F & P-value \\
\cline { 2 - 3 } & Mean (SD) & & \\
\hline Gondar & $4.4(2.5)$ & 4.1 & 0.004 \\
Mekele & $5.0(1.7)$ & - & - \\
Bahir Dar & $3.9(1.3)$ & - & - \\
Shire & $5.0(1.2)$ & - & - \\
Dessie & $5.5(1.9)$ & - & - \\
Total & $4.7(1.7)$ & - & - \\
\hline
\end{tabular}

Abbreviation: SD, standard deviation. 


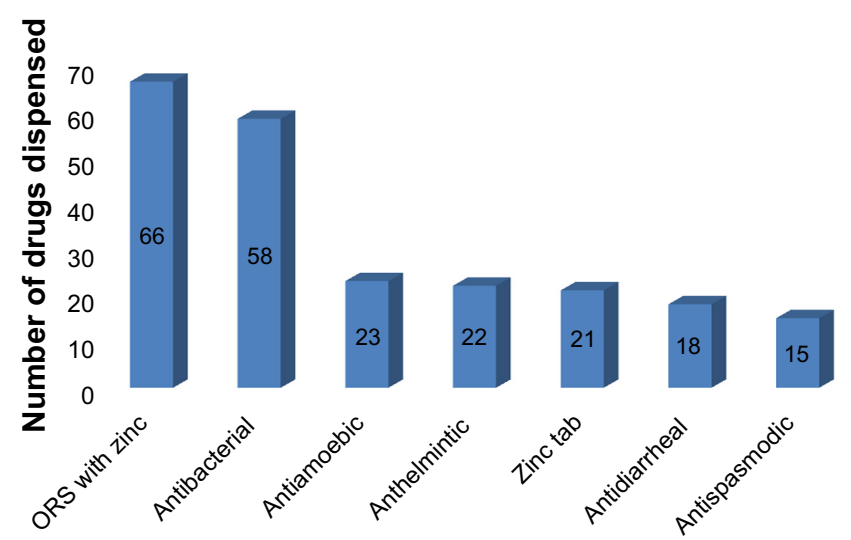

Figure 2 Group of medications used to manage acute childhood diarrhea cases in community pharmacies $(n=1 \mid 3)$.

Abbreviation: ORS, oral rehydration salts.

antibacterial drugs at Mekele. Based on the $\chi^{2}$ test (likelihood ratio), it was found that the groups of medications provided by the pharmacies were different in a statistically significant manner among the five towns except for the case of antiamoebic medicines that did not vary in such a way (Table 4). The mean number of medication was 1.99 per visit. Post hoc analysis test showed significant mean differences between individual towns on the number of drugs recommended per individual diarrheal case. These variations were particularly observed between Dessie $(\mathrm{m}=2.95 \pm 1.40)$ and Mekele $(\mathrm{m}=1.82 \pm 0.59$, $P=0.001)$, Dessie and Bahir Dar $(\mathrm{m}=1.32 \pm 0.77, P=0.00)$, Dessie and Gondar $(\mathrm{m}=1.71 \pm 0.56, P=0.00)$, and Shire and Bahir Dar $(\mathrm{m}=2.35 \pm 0.933, P=0.001)$ (Table 5).

\section{Medication information provided to patients}

In the case of the spectrum of information on how to take the medicines provided by the pharmacies, all five components of advice, such as dose $\left(\chi^{2}=14, P=0.007\right)$, frequency $\left(\chi^{2}=21.4\right.$, $P=0.00)$, duration $\left(\chi^{2}=32.6, P=0.00\right)$, drug action $\left(\chi^{2}=32.9\right.$, $P=0.00$ ), and adverse drug reactions (ADRs, $P=0.00$ ), were found to vary among the five towns in a statistically significant level. Doses and frequencies of drugs were frequently given drug information over other advice forms. On the contrary, ADR of medications was occasionally provided to clients (Table 6). The mean number components of drug information was varied between the towns $(F=7.35, P=0.00)$. Post hoc test indicated a significant difference in the number components of drug information provided between individual towns such as Dessie (mean $[\mathrm{SD}]=3.45 \pm 1.1$ ) and Shire (mean $[\mathrm{SD}]=2.35 \pm 0.5$, $P=0.00$ ), Dessie and Bahir Dar (mean $[\mathrm{SD}]=2.64 \pm 0.9, P=0.007$ ), Shire and Mekele (mean $[\mathrm{SD}]=3.41 \pm 0.6, P=0.01$ ), and Mekele and Bahir Dar $(P=0.01)$ (Table 7).

Table 4 Statistical test $\left(\chi^{2}\right.$ test) of the types of drugs provided by community pharmacies for the treatment of acute childhood diarrhea in five towns of Ethiopia, $2015(\mathrm{n}=113)$

\begin{tabular}{|c|c|c|c|c|c|c|c|c|}
\hline \multirow{2}{*}{$\begin{array}{l}\text { Class of } \\
\text { medication }\end{array}$} & \multicolumn{5}{|l|}{ Towns } & \multirow[t]{2}{*}{ Total } & \multirow[t]{2}{*}{$x^{2}$} & \multirow[t]{2}{*}{$P$-value } \\
\hline & Gondar & Mekele & Bahir Dar & Shire & Dessie & & & \\
\hline \multicolumn{9}{|l|}{ Antiamoebic } \\
\hline Yes (\%) & $2(9.5)$ & $6(27.3)$ & $4(14.3)$ & $2(10)$ & $9(40.9)$ & $23(20.4)$ & 9.5 & 0.51 \\
\hline No (\%) & $19(95.5)$ & $16(73.7)$ & $24(85.7)$ & $18(90)$ & $13(59.1)$ & $90(79.6)$ & & \\
\hline \multicolumn{9}{|l|}{ Antibacterial } \\
\hline Yes (\%) & $17(80.9)$ & $4(18.2)$ & $21(75)$ & $18(90)$ & $12(54.5)$ & $58(5 \mid .3)$ & 40.4 & $0.00 * *$ \\
\hline No (\%) & $4(19.1)$ & $18(81.8)$ & $7(25)$ & $2(10)$ & $10(45.5)$ & 55 (48.7) & & \\
\hline \multicolumn{9}{|l|}{ Antidiarrheal } \\
\hline Yes (\%) & $0(0)$ & $0(0)$ & $6(2 \mid .4)$ & $0(0)$ & $12(54.5)$ & $18(15.9)$ & 39.7 & $0.00 * *$ \\
\hline No (\%) & $21(100)$ & $22(100)$ & $22(78.6)$ & $20(100)$ & $10(45.5)$ & $95(84.1)$ & & \\
\hline \multicolumn{9}{|l|}{ Anthelmintic } \\
\hline Yes (\%) & $0(0)$ & 7 (3I.8) & $5(17.8)$ & $0(0)$ & $10(45.5)$ & $22(19.5)$ & 27.3 & $0.00 * *$ \\
\hline No (\%) & $21(100)$ & $15(68.2)$ & $23(82.2)$ & $20(100)$ & $12(54.5)$ & 91 (80.5) & & \\
\hline \multicolumn{9}{|l|}{ Antispasmodic } \\
\hline Yes (\%) & I (4.7) & $2(9.1)$ & $3(10.7)$ & $0(0)$ & $9(40.9)$ & $15(13.3)$ & 18.2 & $0.01 * *$ \\
\hline No (\%) & $20(95.3)$ & $20(90.9)$ & $25(99.3)$ & $20(100)$ & $13(59.1)$ & $98(86.7)$ & & \\
\hline \multicolumn{9}{|l|}{ ORS with zinc } \\
\hline Yes (\%) & $14(66.6)$ & $20(90.9)$ & II (39.3) & $13(65)$ & $8(36.4)$ & $66(58.4)$ & 21 & $0.00 * *$ \\
\hline No (\%) & $7(33.4)$ & $2(9.1)$ & $17(60.7)$ & $7(35)$ & $14(63.6)$ & $47(4 \mid .6)$ & & \\
\hline \multicolumn{9}{|l|}{ Zinc } \\
\hline Yes (\%) & $2(9.5)$ & $0(0)$ & $0(0)$ & $10(50)$ & $9(40.9)$ & $21(18.6)$ & 37.8 & $0.00 * *$ \\
\hline No (\%) & $19(95.5)$ & $22(100)$ & $28(100)$ & $10(50)$ & $13(59.1)$ & $92(81.4)$ & & \\
\hline
\end{tabular}

Note: **Significant at 0.01 .

Abbreviation: ORS, oral rehydration salts. 
Table 5 Statistical test (one-way ANOVA) of the mean number of medications given by community pharmacies at each diarrheal visit in five towns of northern Ethiopia in 2015 ( $n=113)$

\begin{tabular}{llll}
\hline Town of pharmacy location & Mean (SD) & $\boldsymbol{F}$ & P-value \\
\hline Gondar & $1.71(0.56)$ & $\mathrm{II} .7$ & 0.000 \\
Mekele & $1.82(0.59)$ & - & - \\
Bahir Dar & $1.32(0.77)$ & - & - \\
Shire & $2.35(0.933)$ & - & - \\
Dessie & $2.95(1.40)$ & - & - \\
Total & $1.99(1.05)$ & - & - \\
\hline
\end{tabular}

Abbreviations: ANOVA, analysis of variance; $S D$, standard deviation.

\section{The type of instruction provided on food and fluid intake}

Generally, advice regarding food intake was less frequently given (35) than fluid intake (57). Instructions were not given at all at Shire town on food intake. Only one instruction was provided at Mekele. In contrast, community pharmacies at Dessie and Bahir Dar advised their clients on food intake than others. Regarding fluid intake, around one-half (56, 49.6\%) of them did not get any information. Incorrect information was given for 17 cases $(15.0 \%)$ regarding fluid intake (Figures 3 and 4) (Table 6). Significant differences occurred in all cities with regard to the provision of food $\left(\chi^{2}=59.2\right.$, $P=0.00)$ and fluid $\left(\chi^{2}=31.8, P=0.00\right)$ instruction (Table 8$)$.
Types of measures taken by community pharmacies upon encountering acute diarrhea case (outcome from visit)

Out of 113 acute diarrheal cases presented to community pharmacies, 96 cases $(85.0 \%)$ were provided with one or more medications. The remaining 17 cases (15\%) did not receive any medication that included both referral to nearby hospital or clinic and discharge with neither medication nor referral (Table 8 ). pharmacists frequently provided medications $58(51.3 \%)$ than did druggists 38 (33.6\%) (Table 8). However, in the binary logistic regression test, location of pharmacy (crude odds ratio [COR] $[95 \% \mathrm{CI}]=1.7[0.59$ 4.91], adjusted odds ratio [AOR] [95\% CI] $=2.32[0.67-2.9])$ and qualification of pharmacy professionals $(\mathrm{COR}=1.1$ [0.37-3.1], AOR $=0.89$ [0.27-2]) who dispensed medications were not found to have a statistically significant effect on the outcome of the visit. However, among the different towns in the study, pharmacies located at Shire $(\mathrm{COR}=10.86$ [1.22-97.1], AOR = 15.7 [1.50-153.7]) demonstrated nearly 16 times more chance for providing medications than those in Dessie town. As can be seen from Table 8, nearly all pharmacies dispensed medication at Shire. Although pharmacies in Mekele and Bahir Dar showed statistically significant predicting effects on dispensing of medicines compared to

Table 6 Statistical test $\left(\chi^{2}\right.$ test) of drug information provided by community pharmacies during acute childhood diarrhea management in five towns of northern Ethiopia, $2015(n=1 \mid 3)$

\begin{tabular}{|c|c|c|c|c|c|c|c|c|}
\hline \multirow{2}{*}{$\begin{array}{l}\text { Drug information } \\
\text { and instruction }\end{array}$} & \multicolumn{5}{|l|}{ Town } & \multirow[t]{2}{*}{ Total } & \multirow[t]{2}{*}{$\chi^{2}$} & \multirow[t]{2}{*}{$P$-value } \\
\hline & Gondar & Mekele & Bahir Dar & Shire & Dessie & & & \\
\hline \multicolumn{9}{|l|}{ Dose } \\
\hline Yes (\%) & $19(90.5)$ & $22(100)$ & $25(89.3)$ & $20(100)$ & $16(72.7)$ & $102(903)$ & 14 & $0.007^{* *}$ \\
\hline No (\%) & $2(9.5)$ & $0(0)$ & $3(10.7)$ & $0(0)$ & $6(27.3)$ & II (9.7) & & \\
\hline \multicolumn{9}{|l|}{ Frequency } \\
\hline Yes (\%) & $19(90.5)$ & $22(100)$ & $27(96.4)$ & $20(100)$ & $14(63.6)$ & $102(90.3)$ & 21.4 & $0.00 * *$ \\
\hline No (\%) & $2(9.5)$ & $0(0)$ & I (3.6) & $0(0)$ & $8(36.4)$ & II (9.7) & & \\
\hline \multicolumn{9}{|l|}{ Duration } \\
\hline Yes (\%) & $19(90.5)$ & $22(100)$ & $17(60.7)$ & $7(35)$ & $17(77.3)$ & $82(72.6)$ & 32.6 & $0.00 * *$ \\
\hline No (\%) & $2(9.5)$ & $0(0)$ & II (39.3) & $13(65)$ & $5(22.7)$ & 31 (27.4) & & \\
\hline \multicolumn{9}{|l|}{ Drug action } \\
\hline Yes (\%) & $3(14.3)$ & $8(36.4)$ & $23(82.1)$ & $20(100)$ & $15(68.9)$ & $31(27.4)$ & 32.9 & $0.00 * *$ \\
\hline No (\%) & I8 (85.7) & $14(63.6)$ & $5(17.9)$ & $0(0)$ & $7(3 \mid . I)$ & $82(72.6)$ & & \\
\hline \multicolumn{9}{|l|}{ ADR } \\
\hline Yes (\%) & $0(0)$ & I (4.5) & $0(0)$ & $0(0)$ & $14(63.6)$ & $15(13.3)$ & 51.5 & $0.00 * *$ \\
\hline No (\%) & $21(100)$ & $21(95.5)$ & $28(100)$ & $20(100)$ & $8(36.4)$ & $98(86.7)$ & & \\
\hline \multicolumn{9}{|l|}{ Advise on fluid intake } \\
\hline Yes (\%) & $16(76.2)$ & $4(18.9)$ & $7(25)$ & $13(65)$ & 17 (77.3) & $57(50.4)$ & 31.8 & $0.00 * *$ \\
\hline No $(\%)$ & $5(23.8)$ & $18(81.1)$ & $21(75)$ & $7(35)$ & $5(22.7)$ & $56(49.6)$ & & \\
\hline \multicolumn{9}{|l|}{ Advise on food intake } \\
\hline Yes (\%) & $12(57.1)$ & I (4.5) & $4(14.3)$ & $0(0)$ & I8 (8I.8) & $35(30.9)$ & 59.2 & $0.00 * *$ \\
\hline No (\%) & 9 (42.9) & $21(9.5)$ & 24 (85.7) & $20(100)$ & $4(I 8.2)$ & $78(69.1)$ & & \\
\hline
\end{tabular}

Note: **Significant at 0.01 .

Abbreviation: ADR, adverse drug reaction. 
Table 7 Statistical test (one-way ANOVA) of the variation in mean number of drug information provided by community pharmacies at each acute diarrhea visit in five towns of northern Ethiopia, $2015(n=113)$

\begin{tabular}{llll}
\hline Towns & Mean (SD) & $\boldsymbol{F}$ & P-value \\
\hline Gondar & $2.86(0.9)$ & 7.35 & 0.00 \\
Mekele & $3.41(0.6)$ & & \\
Bahir Dar & $2.64(0.9)$ & & \\
Shire & $2.35(0.5)$ & & \\
Dessie & $3.45(1.1)$ & & \\
Total & $2.93(0.9)$ & \\
\hline
\end{tabular}

Abbreviations: ANOVA, analysis of variance; SD, standard deviation.

Dessie in the univariate analysis, they lost statistical significance in the multivariate analysis when controlled for confounders (Table 8). Patients either provide medication or refer to clinicians. Nonetheless, they usually prefer dispensing a regimen than referral (11.5\%) (Figure 5).

\section{Discussion}

Community pharmacies solve a great deal of public health problems in developing countries as they are found close to the community. ${ }^{11}$ This study has tried to point out (elucidate) the contemporary practices of these health facilities in the management of acute childhood diarrhea in northern Ethiopia through simulated cases. It was found that community pharmacies located in the five towns of northern Ethiopia practiced different history taking, drug recommendation, drug information, and food instruction skills to manage acute childhood diarrhea. They were usually located away from hospitals and health centers. The number of druggists was more than the pharmacists. With regard to history taking, community pharmacies poorly investigated the chief complaint of cases $(16.5 \%)$. As the

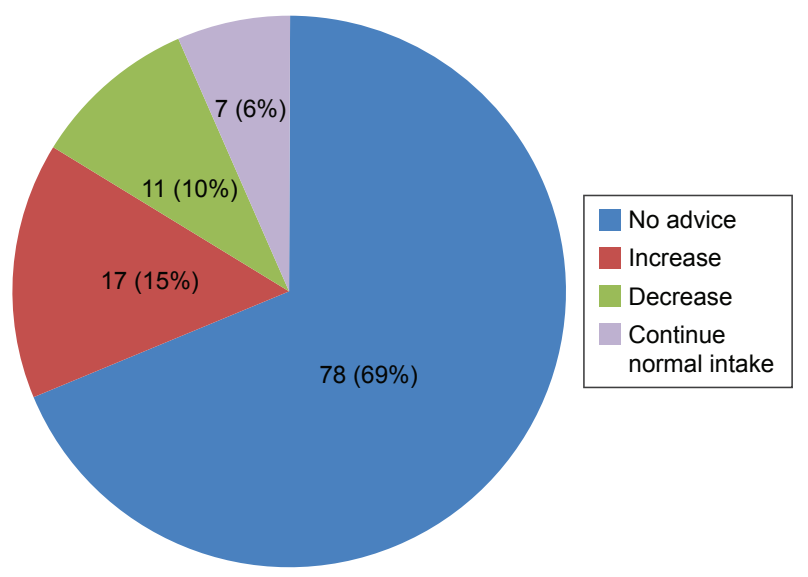

Figure 3 Types of food instructions provided to acute diarrhea cases in community pharmacies $(n=|| 3)$.

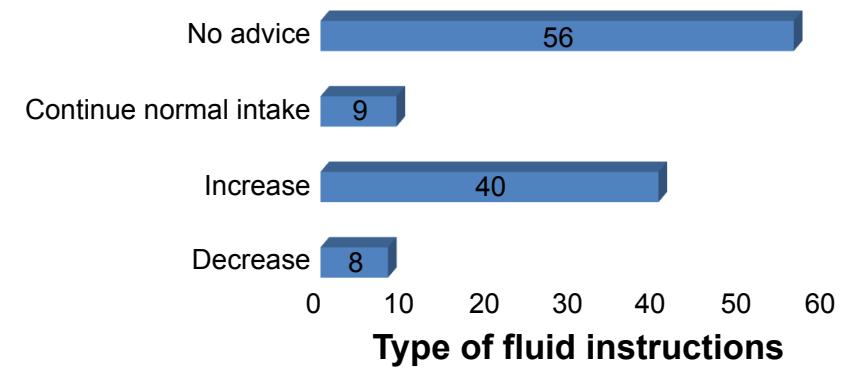

Figure 4 Types of fluid instructions provided to acute diarrhea cases in community pharmacies $(n=\mid 13)$.

name implies chief complaint is the reason for the patient to visit the health care provider. Eliciting the chief complaint would provide insight to patients' disease state and proper management of acute diarrhea cases. Practitioners used to ask for age rather than searching for the most annoying sign or symptom. Ultimately, age of the child was asked more than $90 \%$ of the time in this study, while Iranian community pharmacists claimed a $98 \%$ proportion of taking patients' age. ${ }^{11}$ Findings from three Pakistan cities indicated that patients' age was enquired in $83.3 \%$ of visits to pharmacies. ${ }^{10}$ Similar study conducted at Ujjain, India, indicated that most pharmacists asked about the age $(98.2 \%)$ of a child and frequency of stools. As to the history of blood or mucus in the stool, more than one-half of cases were inquired for this indicator in this study, while only $9.1 \%$ cases were asked in Ujjain. ${ }^{2}$

A study conducted in Trinidad to assess attitudes of pharmacy personnel has shown a $98.9 \%$ of history taking intentions of pharmacists. ${ }^{12}$ Another study conducted at Lagos, Nigeria, revealed that $92.6 \%$ of pharmacists claimed about the importance of taking duration of diarrhea, frequency of stools, and presence of blood in stool. ${ }^{9}$ An observational study from India has discovered that the proportion of practitioners having best knowledge about signs and symptoms of diarrhea was only $15.53 \%{ }^{13}$ This discrepancy in the practice of history taking could be attributed to the variation in local guidelines, unequal distribution of resources, and lack of training. Training of community pharmacy workers has a significant impact on the appropriate management of common illness. ${ }^{14,15} \mathrm{~A}$ correct illustration of patient's current medical history beyond age and weight will enable dispensers to pass the right decision for their patients. Periodic short-term training on the common manifestations of acute diarrhea is warranted to scale-up both knowledge and attitude of practitioners. A training intervention study has found that significant improvement was noted in the knowledge of dehydration symptoms for diarrhea from $19 \%$ to $88 \%$ 
Table 8 The determinants of medication recommendation by community pharmacies for simulated acute diarrhea case in five towns of northern Ethiopia, 2015 ( $n=113)$ : a binary logistic regression

\begin{tabular}{|c|c|c|c|c|}
\hline \multirow[t]{2}{*}{ Variable } & \multicolumn{2}{|l|}{ Outcome from visit } & \multirow[t]{2}{*}{ Crude OR $(95 \% \mathrm{Cl})$} & \multirow[t]{2}{*}{ Adjusted OR $(95 \% \mathrm{CI})$} \\
\hline & Dispensed 96 (85\%) & Not dispensed I7 (15\%) & & \\
\hline \multicolumn{5}{|l|}{ Location of pharmacy } \\
\hline Near hospital & $28(24.7)$ & $7(6.1)$ & $1.7(0.59-4.91)$ & $2.32(0.67-2.9)$ \\
\hline Away from hospital & $68(60.1)$ & $10(9.1)$ & I & I \\
\hline \multicolumn{5}{|l|}{ Dispenser qualification } \\
\hline Pharmacist & $58(5 \mathrm{I} .3)$ & $10(8.8)$ & I.I (0.37-3.I) & $0.89(0.27-2.9)$ \\
\hline Druggist or lower & $38(33.7)$ & $7(6.2)$ & I & I \\
\hline \multicolumn{5}{|l|}{ Town } \\
\hline Gondar & $18(15.9)$ & $3(2.8)$ & $3.43(0.765-15.4)$ & $3.0 \mathrm{I}(0.66-14.4)$ \\
\hline Mekele & $20(17.4)$ & $2(1.8)$ & $5.7 \mid(I .05-3|.|)^{*}$ & $4.68(0.82-26.8)$ \\
\hline Bahir Dar & $25(22.1)$ & $3(2.8)$ & $4.762(1.05-20.9)^{*}$ & $4.11(0.9-18.7)$ \\
\hline Shire & $19(16.8)$ & I (0.9) & $10.86(1.22-97.1)^{*}$ & I5.7 (I.50-I53.7)* \\
\hline Dessie & $14(12.4)$ & $8(7)$ & 1 & I \\
\hline
\end{tabular}

Note: *Significant at 0.05

Abbreviations: $\mathrm{OR}$, odds ratio; $\mathrm{Cl}$, confidence interval.

after engaging pharmacy personnel on a knowledge-bearing workshop. ${ }^{16}$ One-way analysis of variance test indicated that history taking was varied across towns. It was better performed at Dessie over other towns. However, post hoc analysis revealed statistical difference in history taking only between Dessie (mean $\mathrm{SD}=5.5 \pm 1.9$ ) and Bahir Dar (mean $\mathrm{SD}=3.9 \pm 1.3, P=0.004)$. The significant difference in the extent of history taking between towns might be attributed to the difference in adherence of the data collectors to the instructions. ${ }^{17}$

Community pharmacists dispensed a variety of groups of drugs to treat acute childhood diarrhea. Majority (66, $29.6 \%$ ) of the dispensed medications were ORS with zinc. The combination of ORS and zinc has been introduced in Ethiopia to the management of acute childhood diarrhea very recently. Locally, it was distributed to customers as "LEMLEM PLUS". The consumption of this preparation was very low as compared to an ideal use value of $100 \%$

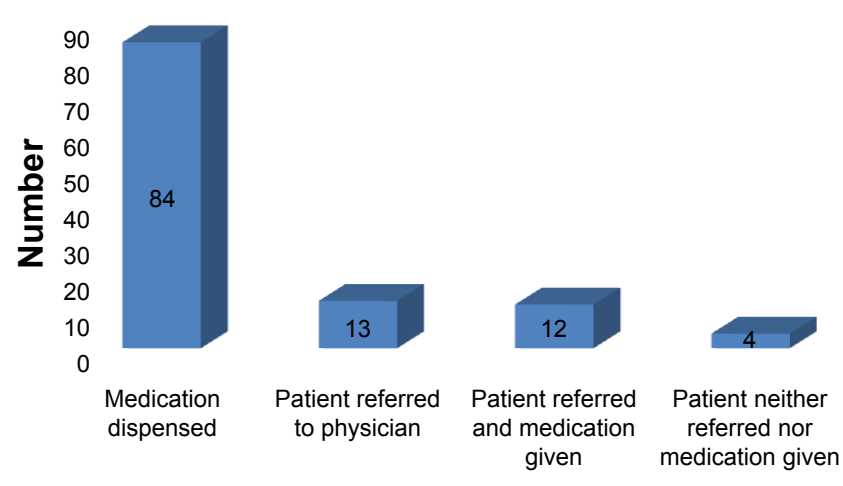

Figure 5 The type of outcome from visit that patients were provided in community pharmacies $(n=|| 3)$. for acute diarrhea.$^{18}$ Community pharmacists did not have equal access to updated guidelines. Hence, they could not acquire the knowledge and the preparation sooner. ${ }^{3}$ However, ORS plus zinc prescription was by far higher in this study as compared to Pakistan cities in which only $<10 \%$ cases received ORS. ${ }^{10}$ In 2010 , WHO estimated that $<60 \%$ children with acute diarrhea in developing countries received ORS, whereas $>40 \%$ received antibiotics. Difference in the rate of use of ORS plus zinc was statistically significant between the towns $(P=0.00)$ in this study. A higher consumption rate of ORS and zinc in Ethiopian towns might be due to the difference in the type of practitioners in which more druggists and pharmacists were available than India and Pakistan cities where salespersons and unlicensed individuals were working. Antibacterial drugs (antibiotics) (58, 26.0\%) were the second most prescribed drugs. Evidences of inappropriate antibiotic use in diarrhea are rising across the globe. A survey in Mexico demonstrated that $37 \%$ of diarrheal cases received antibiotics, although it was indicated only in 5\% of cases. Report from Indonesia showed that $91 \%$ of under-five children received antibiotics. ${ }^{2} 13$ Antibacterial prescription pattern was significantly different between the towns $(P=0.00)$. This inconsistency in antibacterial recommendation could be occurred due to the difference in history taking that is very determinant for drug selection $(P=0.006)$. Based on the appearance of stool and other supportive evidences, pharmacists could prefer one regimen over the other for their patients. ${ }^{19}$

The mean number of combination medication was $\sim 2$ per visit. A large number of combination medications were recommended at Dessie (mean $[\mathrm{SD}]=2.95 \pm 1.4$ ) for every single diarrhea case. In contrast, a low number of combination 
medications were dispensed to diarrheal cases presented at Bahir Dar town. Significant difference existed between the towns on the number of combination medications recommended $(P=0.00)$. Similar study conducted at Lagos, Nigeria, reported that pharmacists recommended up to five drugs per a single diarrheal case. ${ }^{9}$ A cohort study from the Netherlands has discovered that the majority of children were exposed to one or more drugs, and this exposure started at a very young age. ${ }^{20}$ The observed difference in the number of combination medication depends on the availability and affordability of the product. Some pharmacists might also wish to give more combination drugs so that they would have profit. Patients sometimes forced dispensers to add drugs because they did not consider ORS as a remedy. ${ }^{21}$ Another study reported that the availability of fixed-dose combinations of an antiprotozoal and an antibacterial, for treatment of diarrhea, in the pharmaceutical market might influence the prescription patterns that resulted in higher risks of ADRs, chances of drug resistance, and unaffordable cost. ${ }^{22}$ Even though they did not substantially compromise the quality of prescription, economic factors such as profit, pressures of excess stock, and promotion by sales representatives have been involved in community pharmacists' drug selection. ${ }^{23}$ Drug information, including dose, frequency, duration, drug action, and ADRs, was found to vary among the five towns at a statistically significant level. Clients were appropriately told about the dose and frequency of medications as compared to other information components. Regarding individual town, the community pharmacies at Mekele and Shire provided adequate information on dose and frequency of drugs for all diarrheal encounters. Only 15 (13.3\%) community pharmacies gave cautions on adverse drug effects in this study. Important information was missing when treating common ailments including acute diarrhea. A study conducted at Ambo, Ethiopia, has reported that community pharmacists provided wrong strength, frequency, and total quantity of medications. $^{24}$

Inappropriate counseling such as decreasing and taking normal amount was observed regarding food and fluid even though increased intake was recommended by WHO. ${ }^{9}$ Significant differences occurred in all cities concerning the community pharmacies' provision of food $(P=0.00)$ and fluid $(P=0.00)$ instruction (Table 2). The communication between the patient and the pharmacist might determine the quality of instruction. ${ }^{25}$ Even though instructions on oral food and fluid intake are vital to replace the loss of nutrients during acute diarrhea episodes, the actual practice did not show dispensers' commitment to deliver the accurate instruction. The high rate of ignorance (no advice) and misinformation (poor counseling) indicated poor management of diarrhea with nonpharmacologic treatment options such as homemade fluid and breastfeeding because caregivers treat diarrhea on the basis of health care providers' advice. ${ }^{6}$ Similar study results also showed poor community pharmacists' instructions on food and fluid intake. ${ }^{9}$ Diarrhea management practices were unsatisfactory in urban slums of India, where practitioners' knowledge on history taking, drug, and food information was a strong predictor for rational management. ${ }^{13}$ In countries such as Ethiopia in which literacy level is as low as $40 \%$, patients could not understand the role of food and fluid intake. ${ }^{26,27}$ Mothers withheld fluids, breast milk, water, tea, rice-water, and juice, during acute diarrheal illness with associated vomiting because they thought that the fluid would exacerbate the frequency of diarrhea. ${ }^{20,28} \mathrm{~A}$ community-based cross-sectional study conducted at Assosa, West Ethiopia, reported similar findings in which parents stopped feeding liquid-containing food items when their child had diarrhea. ${ }^{29}$ Community pharmacies were supposed to fill this knowledge and attitude gap of the community so that proper management of diarrhea could be achieved. However, the inadequate understanding of dispensers about the right food and fluid intake recommendations might hinder the delivery of the right counseling tip to the patient.

The extent of dispensing drugs for each diarrhea case was nearly 16 times more likely at Shire (AOR $=15.7,95 \%$ $\mathrm{CI}=1.5-153.7)$ than that at Dessie town. As shown in Table 1, nearly all pharmacies dispensed medication at Shire. This indicated that patients were rarely referred or discharged without medication. Dispensers usually did a referral for laboratory investigations that could determine the extent of medication provision. The overall rate of medication dispensed was 96 (85\%) in this study (Table 8). It was slightly higher than that in Trinidad that reported a $77.1 \%$ rate. Community pharmacies should limit the extent of drug provision to those cases with confirmed diagnosis. Incomplete and ambitious patients' disease information should be deferred or ruled out ahead of medication recommendation. This can be achieved when management is supported by objective findings and appropriate history taking so that antibiotic exposure and resistance will be reduced.

\section{Limitation of the study}

This study was a onetime survey of the management of acute diarrhea by community pharmacies. Hence, it lacked some sort of comprehensiveness to evaluate the performance of all dispensers, in case more than one practitioner was working in a single community pharmacy. 


\section{Conclusion}

Community pharmacies provided inadequate therapy for acute childhood diarrhea. Noncomprehensive history taking and incorrect drug and food instructions have been frequently observed during acute diarrhea management. Practitioners working in northern Ethiopia community pharmacies should receive appropriate training on the management of acute childhood diarrhea. The Amhara and Tigray regional health bureau could also supply updated guidelines and call these professionals for conferences and meetings to share experience among them. Information dissemination through reliable social media on the latest changes in the mode of treatment of diarrhea can significantly improve the quality of care delivered for patients. Intervention at this health care unit could substantially reduce admissions due to severe acute malnutrition, associated infections, mental retardation, and premature death of children.

\section{Acknowledgments}

The authors wish to thank all community pharmacies for their contribution and further thank all the faculty members of the School of Pharmacy, College of Medicine and Health Sciences, University of Gondar. This study was not associated with any financial support.

\section{Author contributions}

All authors contributed toward data analysis, drafting and critically revising the paper and agree to be accountable for all aspects of the work.

\section{Disclosure}

The authors report no conflicts of interest in this work.

\section{References}

1. Moorthi C, Rachel P, Senthilkumar C. Knowledge of community pharmacist in the management of diarrhea in adults. Pharm Lett. 2011;3(1): 364-370.

2. Diwan V, Sabde YD, Byström E, De Costa A. Treatment of pediatric diarrhea: a simulated client study at private pharmacies of Ujjain, Madhya Pradesh, India. J Infect Dev Ctries. 2015;9(5):505-511.

3. Federal Ministry of Health (FMOH) of Ethiopia [webpage on the Internet]. Federal Ministry of Health, Ethiopia Development of National Acute Water Diarrhea Prevention and Control (NAWDPC) Strategy. 2010. Available from: http://www.moh.gov.et. Accessed September 21, 2015.

4. Godana W, Mengistie B. Determinants of acute diarrhoea among children under five years of age in Derashe District, Southern Ethiopia. Rural Remote Health. 2013;13(2329):1-11.

5. Nigussie WD. Patient counselling at dispensing of medicines in health care facility outpatient pharmacies of Bahir Dar City, Northwest Ethiopia. Sci J Public Health. 2014;2(2):126.

6. Emily C, Jennifer B, Jamie P, Holly N. Harmful practices in the management of childhood diarrhea in low- and middle-income countries: a systematic review. BMC Public Health. 2015;15:788.
7. Pham DM, Byrkit M, Pham HV, Pham T, Nguyen CT. Improving pharmacy staff knowledge and practice on childhood diarrhea management in Vietnam: are educational interventions effective? PLoS One. 2013; 8(10): 74882.

8. Chisholm-Burns MA, Kim Lee J, Spivey CA, et al. US pharmacists' effect as team members on patient care: systematic review and metaanalyses. Med Care. 2010;48(10):923-933.

9. Ogbo PU, Aina BA, Aderemi-Williams RI. Management of acute diarrhea in children by community pharmacists in Lagos, Nigeria. Pharm Pract (Granada). 2014;12(1):376.

10. Hussain A, Ibrahim M. Management of diarrhoea cases by community pharmacies in 3 cities of Pakistan. East Mediterr Health J. 2012;18(6): 635-640.

11. Golnaz V, Azadeh E, Neda E, Moein M, Maryam M, Nazanim E. Management of acute diarrhea. A study on community pharmacists' attitude in Iran. Rev Recent Clin Trials. 2015;10(2):155-160.

12. Karim R, Ramdahin P, Boodoo JR, Kochhar A, Pinto Pereira LM. Community pharmacists' knowledge and dispensing recommendations for treatment of acute diarrhoea in Trinidad, West Indies. Int J Clin Pract. 2004;58(3):264-267.

13. Tanmay M, Sanchita M, Barnali B, et al. Predictors of rational management of diarrhea in an endemic setting: observation from India. PLoS One. 2015;10(4):1-13.

14. Hussain A, Izham Mohamed Ibrahim M, Malik M. Impact of training of dispensers on case management of acute respiratory tract infections at community pharmacies in Pakistan. Pharmacol Pharm. 2012; 3:485-491.

15. Saengcharoen W, Sanguan Lerkiatbundit S. Migraine management in community pharmacies: practice patterns and knowledge of pharmacy personnel in Thailand. Headache. 2013;53:1451-1463.

16. Minh PD, Huong DTM, Byrkit R, Byrkit R, Murray M. Strengthening pharmacy practice in Vietnam: findings of a training intervention study. Trop Med Int Health. 2013;18(4):426-434.

17. Akwagyriam I, Goodyer LI, Harding L, Khakoo S, Millington H. Drug history taking and the identification of drug related problems in an accident and emergency department. J Accid Emerg Med. 1996;13: $166-168$.

18. Federal Democratic Republic of Ethiopia DRE Ministry of Health [webpage on the Internet]. Assessment of the Pharmaceutical Sector in Ethiopia. 2003. Available from: http://www.who.int/medicines/areas/ coordination/ethiopia_pharmaceutical.pdfis. Accessed September 21, 2015.

19. Yusuff KB, Tayo F, Aina BA. Pharmacists' participation in the documentation of medication history in a developing setting: an exploratory assessment with new criteria. Pharm Pract (Granada). 2010;8(2): 139-145.

20. Schirm E, van den Berg P, Gebben H, Sauer P, De Jong-van den Berg L. Drug use of children in the community assessed through pharmacy dispensing data. Br J Clin Pharmacol. 2000;50: 473-478.

21. Zwisler G, Simpson E, Moodley M. Treatment of diarrhea in young children: results from surveys on the perception and use of oral rehydration solutions, antibiotics, and other therapies in India and Kenya. J Glob Health. 2013;3(1):010403.

22. Chakrabarti A. Prescription of fixed dose combination drugs for diarrhoea. Indian J Med Ethics. 2007;4(4):165-167.

23. Kennedy E, Moddy M. An investigation of the factors affecting community pharmacists' selection of over the counter preparations. Pharm World Sci. 2000;22(2):47-52.

24. Jimma LL, Biruk M, Minyahil AW, et al. Analysis of dispensing practices at community pharmacy setting in Ambo Town, West Shewa, Ethiopia. J Community Med Health Educ. 2015;5:1.

25. Ware KB. Prescription for progress-enhancing communication between pharmacists and patients. SOJ Pharm PharmSci. 2014;1(1): $1-2$.

26. Leong C, Louizos C, Frankel G, et al. A physical assessment skills module on vital signs. Am J Pharm Educ. 2014;78(7):137. 
27. Federal Ministry of Health [webpage on the Internet]. Health and Health Related Indicators. 2014. Available from: http://www.moh.gov.et/ documents/26765/0/Health+and+Health+Related+Indicators+2005+E. C/1b5b2a9f-a960-4024-8d92-519195364023. Accessed September 21, 2015.

28. Mediratta RP, Feleke A, Moulton LH, Yifru S, Sack RB. Risk factors and case management of acute diarrhoea in North Gondar Zone, Ethiopia. J Health Popul Nutr. 2010;28(3):253-263. Available from: http://www. ncbi.nlm.nih.gov/pubmed/20635636. Accessed September 21, 2015.
29. Merga N, Alemayehu T. Knowledge, perception, and management skills of mothers with under-five children about diarrhoeal disease in indigenous and resettlement communities in Assosa District, Western Ethiopia. J Health Popul Nutr. 2015;33(1):20-30.

\section{Publish your work in this journal}

Therapeutics and Clinical Risk Management is an international, peerreviewed journal of clinical therapeutics and risk management, focusing on concise rapid reporting of clinical studies in all therapeutic areas, outcomes, safety, and programs for the effective, safe, and sustained use of medicines. This journal is indexed on PubMed Central, CAS,
EMBase, Scopus and the Elsevier Bibliographic databases. The manuscript management system is completely online and includes a very quick and fair peer-review system, which is all easy to use. Visit http://www.dovepress.com/testimonials.php to read real quotes from published authors.

Submit your manuscript here: http://www.dovepress.com/therapeutics-and-clinical-risk-management-journal 